\title{
Sanatın Sosyolojik İmkânı
}

\author{
Yazar: Kenan Çă̆an \\ Yayın Evi: Pruva Yayınlarl, Ankara, 2020, 248
}

Ayhan Koçkaya ${ }^{1}$

Kenan Çağan'ın, ilk baskısı 2020 yılında yapılan Sanatın Sosyolojik İmkânı kitabı, “Giriş” (7), “Sanat Sosyolojisi” (13-64), "Sanat ve Siyaset” (73-229), "Kaynakça" (229) ve "Dizin" (239) ana bölümlerinden oluşuyor. Kitabın "Giriş" bölümünde Kenan Çağan "sanat sosyolojisiz bir sosyolojinin önemli derecede eksik kalacağı”nı söyledikten sonra sanat sosyolojisinin “soluk görünümü”nü şu iki nedenle açıklıyor:

a. sanat sosyolojisi sahasinda eserler veren sosyal bilimcilerin sosyolog olarak kendilerine yer açamamaları,

b. bu sahada verilen eserlerin, sosyolojinin seyri üzerinde tesir meydana getirecek vasıflara ulaşamamış olmasi.

Bunlara ek olarak Kenan Çağan, "Giriş” kısmının sonlarında bu kitabın, edebî eserlerden hareketle Türk modernleşmesinin istikameti, tahlil ve tenkidi, edebiyat ve sosyoloji münasebeti, edebiyatın ulus inşasındaki rolü, edebiyatın toplumları dönüştürme potansiyeli vd. konulara temas edeceğini belirtmektedir.

Çağan, sanat sosyolojisinin, on dokuzuncu asırdaki sosyologlar tarafindan alâka görmediğini de kitabın bu ilk kısmında ifade etmektedir. (Hemen ardından da bu umumî kayıtsızlı̆̆a iki istisnanın Max Weber ile Georg Simmel olduğunu da dile getirmektedir.) Ayrıca Kenan Çağan, yine bu bölümde sanat sosyolojisinin daha öncesinde üç farklı safhadan geçtiğini ve halihazırda dördüncü bir safhayı tecrübe etmekte olduğunu belirtmektedir, ki bu tespit sanat sosyolojisi hakkında yeni okumalar yapmaya başlayanlar için önemli

\footnotetext{
${ }^{1}$ Sakarya Üniversitesi, Sosyoloji Bölümü, Sakarya, Türkiye, kockaya@ sakarya.edu.tr, ORCID ID: 0000-0001-9131-4037

Received: 01 March 2021, Accepted: 24 April 2021, Online: 30 April 2021
} 
bir metodolojik katkı sunmaktadır. Sanat sosyolojisinin birinci evresinde sanata bir misyon yüklenmiştir ve bu misyon toplumu iyileştirme misyonudur. Çağan'ın deyişiyle bu safha "sanata değer yönelimli bir yaklaşım” safhasıdır. İkinci safhanın gelişim safhası olduğu belirtilmektedir ve Çağan bu dönemde "sanatı somut toplum içerisinde görmeye çalışan" yaklaşımın hakim olduğunu nakletmektedir. Yirminci asrın ilk yarısının sonlarında sanat sosyolojisinin üçüncü safhası başlar ve bu safhada sosyal bilimciler sanat dünyasının bizatihî kendisine odaklanır. Ayrıca bu dönemde sanat eseri kolektif bir sürecin ürünü olarak görülmeye başlanır. Kenan Çağan, sanat sosyolojisinde dördüncü safhanın başladığını iddia edenlerin "kültür üretimi teorisi”, "arabuluculuk teorisi” ve "cinsiyet araştırmaları"na istinat ettiğini söylemektedir.

Kitabın "Sanat Sosyolojisi” başlıklı birinci kısmında (s. 15-71) yer alan "Sanat Sosyolojisinin Tarihi Seyri” başlıklı bölümde sanat sosyolojisine dair metodik/tarihsel bilgilerin yanı sıra on dokuzuncu yüzyılda yaşamış kimi düşünürlerin sanata dair yaklaşımlarına yer verilmiştir. Bu bölümde, Madame de Stael ve Pierre-Joseph Proudhon'un sanat alanındaki yorumları sanat sosyolojisine dair öncü yaklaşımlar arasında zikredilmektedir. Özellikle Proudhon sanat ve toplum etkileşimini inceleyen ve kuşatıcı bir teori geliştirme teşebbüsünde bulunan bir düşünür olarak ele alınmakta ve kendisinin sanata "toplumu mükemmelleştirme” misyonu yüklediği ifade edilmektedir. Çağan'ın (sanat sosyolojisindeki) “öncü kuşak” dediği bu düşünürlerin yanı sıra Jean-Marie Guyau gibi teorisyenler de sanatı işlevsel bir olgu olarak görmektedirler. Ayrıca aynı bölümde Thorstein Veblen' in, sanatı “zenginlerin özel zevki ve ekonomik pazarın yasalarına tabi bir ticari ürün olarak değerlendir"diği de dile getirilmiştir. Bu yüzyılı kat edip yirminci yüzyıla geldiğimizde ise sanata dair en kayda değer yaklaşımların Frankfurt Okulu düşünürlerince serd edildiği görülmektedir. Kitap Frankfurt Okulu düşünürlerinin sanatı nasıl değerlendirdiği, sanatı geleneksel Marksist yorumdan farklı bir şekilde yorumladıkları anlatılmaktadır. Söz konusu düşünürler altyapı-üstyapı diyalektiğini aşan bir okumayla sanatı yorumlar, sanatı "direnişin ve gerçekliğin kalesi”" olarak görür (s.21).

Sanat sosyolojisinin ikinci safhasının, bu alanın görev ve yöntemi konusunda yapılan tartışmalarla eş zamanlı olarak başladığı da birinci kısımda işlenmektedir. Bu ikinci safhada bir toplumdaki maddî koşulların değişmesiyle sanat üretimi ve tüketimi arasındaki ilişki, sanatçının statüsü ve bu statünün geçirdiği değişimlerin inceleme konusu olduğu belirtilmektedir. (s. 23 - 25).

Sanat sosyolojisinin üçüncü safhası, bu safhanın ikincisiyle olan geçişkenliği, üçüncü safhanın (Pierre Bourdieu, Howard S. Becker ve Niklas Luhmann gibi) düşünürleri anlatılmakta, bu dönemde yapılan ampirik çalışmalara da aynı bölümde temas edilmektedir. Kenan Çağan, Bourdieu gibi sosyal bilimcilerin yaptığı ampirik çalışmalarda sanat faaliyetiyle sınıf arasındaki ilişkiyi göstermeye çalıştığını belirtmektedir. 
Üçüncü safha sanat sosyolojisi çalışmalarında Bourdieu önemli bir konuma sahiptir, zira bir toplumdaki insanların hangi sanat eserini neden tercih ettiğini anlamaya çalışan araştırmalar gerçekleştirmiştir. Öte yandan sanatın geçirdiği ontolojik dönüşüm de üçüncü kuşak sanat sosyolojisinin önemli bir özelliği olarak belirtilmektedir. Artık sanat kolektif bir eylem görülmekte ve sanatçı da sanat eserinin yegâne üreticisi olarak değerlendirilmemektedir. Kenan Çağan her üç düşünürün de sanatı tek bir kişinin üretimi olarak görmediğini ifade etmektedir, artık söz konusu olan, tamamen toplumdan ve bütün üretim ilişkilerinden bağımsız, izole bir "Sanatçı" değil "bir insan havuzu"dur (s. 26 - 33). "Tanım ve Sınırlılıklar" (s. 34 - 39) başlıklı bölüm sanat sosyolojisinin imkânını ve en başından beri yaşadığı temel zorlukları ele almakta ve tartışmaktadır. Bu bölümün sonuna doğru ise sanat sosyolojisinin nesnesini nasıl seçeceği, "toplumsal gerçeklikle" olan ilişkisi, sanat faaliyeti ile toplum arasındaki ilişkiyi kapsayan bir alan oluşu ele alınmaktadır. Öte yandan sanat sosyolojisinin, edebiyat sosyolojisinin gölgesi altında kalıyor oluşu bir çeşit handikap, aşılamamış de facto bir durum olarak belirtilmektedir. Bu durum edebiyat sosyolojisinin sanat sosyolojisi üzerine uyguladığı bir "baskı" olarak adlandırılmaktadır (s.37).

“Alanı Belirlemek: Üretim, Aracılık ve Kabul” başlıklı bölümde (s. 39 - 51) sanat sosyolojisinin çalışma alanlarının ne olduğu nakledilmektedir. Bu bölümde Kenan Çağan, cevaplanması gereken temel bazı soruların altını çizmektedir. "Sanatçı kimdir?" sorusu bunların arasında yer almaktadır. Burada meslekler sosyolojisi ile sanat sosyolojisi arasında kurulabilecek bir yakınlık dile getirilmektedir. "Sanatın ve sanatçının" konumunun değişkenliği bu bölümde değerlendirilmektedir. Bu noktada Dilthey’e bir atıfla, sanat ile toplumsal tin arasındaki ilişkinin altı çizilmektedir (s. 43 - 45).

Sanat sosyolojisinin üęüncü safhası ile sanatın toplumsal/kolektif bir ürün oluşu paradigması ilerleyen sayfalarda temellendirilir ve sanat eserini toplumla buluşturan "aracı süreç”ler sanatsal üretimin bir parçası olarak ele alınır. Aynı paradigma sanatçıyla alımlayıcı arasındaki ilişkiyle ve aracı kurumun sanat eserine olan tesiriyle de işlenmektedir (s. 48 - 49).

"Geçmiş de Bugüne Dâhil: Toplumda Sanat veya Sanatta Toplum" (s. 51 - 64) başlıklı bölümde sanat sosyolojisinin, önceki dönemlere ait çalışmaları ve yaklaşımları kategorik olarak reddetmemesi gerektiğini dile getirmekte ve sanatla toplum arasındaki ilişkiye temas edilmektedir. Buna göre bir toplumun sanatını doğru anlayabilmek için farklı yapıların anlaşılması son derece belirleyicidir. Sanat ve siyaset arasındaki ilişki de bu bölümde değerlendirilmekte ve her ikisinin birbiri üzerindeki belirleyiciliğinin altı çizilmektedir. Sanat sosyolojisinin görevinin ne olduğunu ve bilgi üretim mekanizmalarını işleyen bu bölümün sonunda sanat sosyolojisinin tarihsel birikimiyle kurması gereken ilişkinin ne olduğuna tekrar temas edilmektedir. Kenan Çağan tarihsel birikimde ayıklama yapılmasında bir beis görmezken sanat 
sosyolojisi alanının fazlasıyla daraltılmasını ise gayri bilimsel olarak nitelendirir. Çağan'a göre yapılması gereken farklı kuşakların sanat sosyolojisine yaptığı katkıları, "sanatın sosyolojik bilgisinin üretilmesinde etkin kullan"maktır.

Kitabın "Sanat ve Siyaset" (s. 73 - 228) bölümü on bir alt başlıktan oluşmakta ve ilk olarak sanat ile toplum ve sanat ile ideoloji arasındaki ilişkiyi ele almaktadır. Bu bölümde Kenan Çağan, Lefebvre’e yaptığı atıfla sanatın toplumsal bir faaliyet olduğunu nakletmekte ve sanatın fert ve toplumla olan karşılıklı etkileşiminin kaçınılmazlığının altını çizmektedir. Buradan hareketle Çağan, toplumsal bir faaliyet olan sanatın, toplumun değerleri tarafından kuşatıldığı neticesine ulaşır. Burada bir yapı-fail ikiliğini işleyen Çağan, sanatın da toplumu dönüştürdüğü şeklindeki kanaatini belirtmektedir. Öte yandan idealist sanat anlayışı da bu bölümde ele alınmaktadır (s.75 - 77).

Kenan Çağan ideolojinin "bir toplumsal grubun resmiyet kazanmış bilinçli inanışları” şeklindeki tanımını nakletmekte ve ideolojinin muhtelif alanlara sızma dirayetinin olduğunu belirttikten sonra (s. 78 79), Todorov'a atıfla sanatın bir ideoloji olduğu düşüncesini ifade etmektedir. Buradan da sanatın ideoloji ile iç içeliği dile getirmektedir. Öte yandan sanatın ideolojiyi dönüştürme gücü de belirtilmiş ve iktidar mekanizmasının sanatın dönüştürücü gücünü yansıttı̆̆ını belirtmiştir. [“sanat her şeyden önce özgürlügüun alanıdır" ifadesi bu bakımdan değerlendirilebillir. (s. - 88)] Kitaptaki "Muktedir kim? Sanat mı, iktidar mı?" başlıklı alt bölüm iktidar temasını işlemekte ve iktidar olgusuyla sanat arasındaki ve "söylem" ile sanat arasındaki ilişkiyi konu edinmektedir (s. 81 - 87). Çağan’a göre sanat ile siyaset arasındaki ilişkinin iyi anlaşılabilmesi için "ideoloji”, "iktidar” ve “devrim” kelimelerinin doğru değerlendirilebilmesi gerekir, zira, örneğin bir siyasî devrim sanatı araç olarak kullanabilir veya sanat devrime bilinçli olarak destek verebilir. Bu bölümde sanatçının gerçeği sadece dile getirmediği, gerçeğe biçim verme hedefinin olduğu belirtilmiştir (s. 89). Sanatın dünyayı (gerçekliği) sadece dile getirmediği, öte yandan dünyayı değiştirme amacının da olduğu Romantik sanat anlayışının savunduğu bir paradigmadır ve buna göre sanat sadece mimetik bir üretim aracı değil, aynı zamanda bir şekil verme vasıtasıdır.

Kitabın “Osmanlı Modernleşmesinde Bir Sapma Olarak 'Bihruz Bey’ Sendromu” (s. 91 - 101) alt başlığı altında, Osmanlı İmparatorluğu’ndaki Batılılaşma ve modernleşme konuları ele alınmaktadır. Modernleşmenin on sekizinci yüzyıldaki süreciyle, on dokuzuncu yüzyıldaki "ideolojik bir dinamiğe dönüşme" süreci arasındaki farka bu bölümde işaret edilmektedir (s. 101). Tanzimat dönemi Osmanlı aydınına da temas eden Çağan, bu aydınların toptan redci veya toptan kabulcü olmadığını dile getirmektedir ve Tanzimat aydınlarının orta yolculuğunun altını çizmektedir (s. 104). Ayrıca Çă̆an, edebiyatla modernleşme arasındaki ilişkiye ve Osmanlı İmparatorluğu’nda edebiyatın modernleşmenin bir aracı 
olarak görüldüğüne dikkat çekmektedir. Bu bölümde, Tanzimat edebiyatının ilk örneklerinin gazeteler aracılığıyla neşredildiğinin altı çizilmektedir. Dolayısıyla gazetelerin çıkması ile modernleşme arasındaki paralellik dikkati çekmektedir (s. 102). On dokuzuncu yüzyılın ikinci yarısından itibaren edebiyatın "yanlış Batılılaşma" olarak da tabir edilen yanının edebiyat metinleri üzerinden tenkid edildiği konusu ele alınmaktadır. Tanzimat edebiyatının temaları ve edebî figürleri “Bihruz Bey Sendromu” başlığı altında tahlil edilmiştir (s. $106-118)$.

Bu dönemde romanın Batılılaşmada ne denli önemli bir unsur olduğu dile getirilmektedir. Kenan Çağan “alafranga züppe"nin koltuğunun altında roman (da) bulundurduğunun altını çizer. Dolayısıyla, bir yandan “yanlış Batılılaşmanın” (müsrif Bihruz Bey veya züppe Felâtun Bey gibi karakterler üzerinden) kıyasıya eleştirildiği roman türünün kendisi modernleşmenin göstergelerinden de biridir. İlk romanlardaki karakter zıtlığg yine bu bölümde ele alınmaktadır. İlk romanlardaki bu karakterlerin gerçek hayatla bağlantısı olduğu İlber Ortaylı' ya yapılan atıfla nakledilmektedir. Örneğin Osmanlı İmparatorluğu’nda gerçekten yaşamış bir Hariciye teşrifatçısı, Felâtun Bey tipine örnek olarak gösterilmektedir (s. 109).

“Türk Düşüncesinde Sentez Arayışları” başlıklı bölümde Osmanlı İmparatorluğu’nun son asrında müşahede edilen ideoloji arayışı ele alınmakta ve Osmanlıcılık, İslâmcılık ve milliyetçiliğin birbirinden yararlandığının altı çizilmektedir. Kenan Çă̆an’a göre hiçbir ideoloji homojen değildir, “farklı tonlara sahiptir" (s. 123). Sonrasında "Doğu-Batı sentezcileri”nin "Doğu” ve "Batı" tasavvurları ele alınmıştır ve “Sinekli Bakkal'ın Egzotizmi ve Doğu-Batı Sentezi” başlığı altında Halide Edip Adıvar'ın Sinekli Bakkal romanı sentezcilik ekseninde okumaya tabi tutulmaktadır. Romanın alegorik yanına temas ettiği satırlarda Çağan, protagonist Rabia ile Peregrini karakterlerinin evlenmesinin "Doğu-Batı sentezinin alegorik bir anlatımı gibi” olduğunu ifade eder (s.129). Çağan, Türk romanını değerlendirirken, Türk romanının milliyetçi ideolojiyi tahkim ettiğini dile getirmektedir. Millî kimliğin oluşumunda Türk romanına önemli bir yer atfedilmektedir. Kenan Çağan’a göre edebiyatın milli kimlik üzerindeki tesiri edebiyat-dil ilişkisi/bağlantısıdır (s. 135). Bununla bağlantılı olarak, Ziya Gökalp’ten Türkçü fikirleri alan Halide Edip'in (s. 136), sadece Sinekli Bakkal'da değil Yeni Turan romanında da siyasî temaları işlediği belirtilmektedir (s. 137). Edebiyat-siyaset-ideoloji ilişkisi okumasının yapıldı̆̆ı bölümün sonunda Halide Edip Adıvar'ın kapsayıcı milliyetçiliğinin Osmanlı İmparatorluğu için bir çözüm olmadı ğı, milliyetçiliğin ve modernliğin "hiyerarşi kurmaya, sınırlar çizmeye” meyyal olduğu tezine yer verilmiştir.

Kitapta "Edebiyat Sosyolojisine Bir Yöntem Arayışı" (s. 161 - 172) başlıklı bölüm, esas itibariyle Mehmet Âkif Ersoy şiirine odaklanmakta ve şiirle sosyoloji arasındaki paralellikleri ele almaktadır. Bu bölümde sanat felsefesine dair yaklaşımlar da dile getirilmektedir. Çağan’a göre sanat sadece mimetik bir 
üretim biçimi değildir, dolayısıyla doğanın temsilinden ibaret de olamaz; sanatın simgeleme fonksiyonu da bulunmaktadır (s. 161). Öte yandan bu bölümde sanat sosyolojisinin neyden ibaret olmadığı da dile getirilmekte, sanat sosyolojisinin sadece edebiyat sosyolojisi olmadığı anlatılmaktadır (s. 162). Kenan Çağan sanatın sosyolojik bilgisini mümkün kılan şeyin sanatın gerçekle kurduğu "zorunlu bağ" olduğunu söylemektedir (s. 163).

Edebiyat sosyolojisinin metin bağımlı olmaması, interdisipliner bir epistemolojiye yaslanması gerektiği dile getirilmektedir. Çağan'a göre, edebiyat veya sanatın "bilimin kuru nesnesi" olmaması edebiyatın "ruhun tezahürlerine ev sahipliği” yapmasından ileri gelmektedir (s. 168). Bu bölümde ele alındığı kadarıyla sanat, toplumla iç içedir ve toplumdan kopuk, kendi fildişi kulesinde, tüm bir tarih ve kültürden bağımsız bir sanatçı yoktur. Sanatın hayatla mutlak bir bağı vardır ve toplumla edebiyat arasında "çift taraflı" bir ilişki söz konusudur. Sanatçı (burada hususen şairlerden bahsedilmektedir) "kültür kodlarını" tevarüs eder ve yapı, sanat eserine bir biçimde sirâyet etmiştir (s. 170).

Şair özelinde sanatçı ile ilgili bu yaklaşımın ardından "Mehmet Âkif Şiirinin Sosyolojik İmkânı" (s. 172) başlıkı bölüme geçilir. Bu bölümde öncelikle Mehmet Âkif Ersoy'a dair biyografik bilgilere yer verilmekte (s. 172 - 174) ve sonrasında Mehmet Âkif'in şiirlerinin sosyolojik bir okuması yapılmaktadır. Kenan Çağan, Mehmet Âkif'in şiirlerindeki zengin sosyolojik malzemenin varlığına dikkat çeker. Âkif'in şiirlerindeki bu zengin malzeme, şairin "dünya görüşü ve ona bağlı olarak şekillenen sanat anlayışı" ile ilişkilendirilmektedir (s. 174). Sezai Karakoç (s. 176 - 178), Orhan Okay (s. 175) ve D. Mehmet Doğan (s. 175) gibi şair ve mütefekkirlere referansla Mehmet Âkif'in sanat anlayışı bu bölümde ele alınmaktadır ve yer yer beyitlerine yer verilmektedir.

Mehmet Âkif Ersoy ile ilgili bir diğer bölüm "Mehmet Âkif'te Toplumsal Kurumlar ve Siyaset" başlı̆̆ını taşımaktadır (s. 185 - 194). Bu bölümde Âkif' in toplumsal sorunlara karşı kayıtsız kalmadığının, tespit ve çözüm noktasında hassasiyet taşıdığının altı çizilmektedir. Bu bölüm sanat hakkındaki görüşleri destekler mahiyettedir. Sanat toplumla bir biçimde iç içe, toplumun "tinini”" aksettiren bir üretim biçimi olarak ele alınmaktadır. Âkif'in de içinde yaşadığı toplumun meselelerine temas etmesi ve sorunların çözümüne dair tekliflerinin olması nesnel tin - sanat - sanatçı arasındaki ilişkinin varlığını teyid eder. Tüm bunlara ek olarak Âkif' in toplumsal meselelere sadece şiirleri yoluyla değil, bizzat "sahaya in"erek de temas ettiği ifade edilmektedir. Ayrıca kitapta “din, eğitim, ekonomi, aile, gündelik yaşam ve ... siyaset”in iç içeliğinin de altı çizilmiştir (s. 188). Kitapta Âkif’in sadece toplumla veya toplum meseleleriyle ilgilenen yanına değil, devlet konusundaki görüşlerine de yer verilmektedir. Örneğin Âkif devletin muhafaza edilmesi gereken bir aygit olduğunu dile getirmekte ve toplumun ancak bu şekilde güçlü bir surette ayakta 
kalabileceğini savunmaktadır (s. 190).

“Edebiyat Sosyolojisi İçin Bir Tipoloji Denemesi” başlıklı bölüm (s. 195 - 213) bir şair portresi çizme denemesidir (s. 197). Burada Novalis ve Heidegger'den İsmet Özel'e kadar farklı asırlarda ve farklı devirlerde yaşamış şair ve filozoflara referansla bir fail olarak şair ve bir tür olarak şiir tasvir edilmekte ve tanımlanmaktadır. Aliye İzzetbegoviç'e atıfla Çağan, şiirin esasında insana dair bir bilgi olduğu tezini nakleder. Buna göre şiir insanın “iç tarafına, gizli köşelerine, sırlarının içine dalan bir bilgi”dir (s. 198).

Kenan Çağan’a göre şair “zıtlıkların vücut bulmuş hali; zıt kutupların mümkün birlikteliği”dir (s. 203). Bu bölümde şair ayrıcalıklı bir fail olarak tasvir edilir ve bir fail olarak "şair" hakkında çok fazla tavsife yer verilmektedir. Novalis'e yapılan bir atıfla, şairin doğayı bilim adamından daha iyi anladığı nakledilmekte (s. 199) ve şair tipinden "güçlü bir sağduyu ve sezgiyle derin bir kavrayışı olan biri” olarak bahsedilmektedir. Âkif bahsiyle tutarlı bir biçimde Çağan, bu bölümde de sanatçının (şairin) "toplumsal bir varlık” olduğunu dile getirmekte ve kendisini toplumsal meselelerden tecrit etmesinin imkânsızlığına temas edilmektedir (s. 206). [Fakat toplum içindeki şairden sadece kalbe hitap eden bir fail olarak bahsedilmektedir. Ayrıca Çă̆an'a göre şair kâr amaçlı iş yapan birisi değildir. Şair bir tüccar değildir ve yegâne meşgalesi, kendisine hiçbir kâr getirmeyen şiir yazma uğraşıdır. (s. 207).]

Kitaptaki son bölüm “Osmanlı’dan Cumhuriyet'e Paradigma Değişiminin Sanatsal İzleri” başlı̆̆ını taşımaktadır (s. 213). Başlıktan da anlaşılabileceği üzere, erken dönem Türkiye Cumhuriyeti’nin müzik politikalarının tahlil edildiği bu bölüm Batılılaşma serencâmının bir diğer veçhesini ele almaktadır. Türkiye Cumhuriyeti’ nin tarihiyle yaşadığı kopuştaki benzersizliği değerlendirilmekte ve erken cumhuriyetin kültür politikalarının “Batılılaşma hedefleri arasındaki ilişki”si incelenmektedir (s. 217). 1930’lu yıllardan itibaren kurulan kimi müesseselerin Batılılaşma yolunda atılan adımlarla ilişkisine temas edilmekte ve bu müesseselerin fonksiyonelliği (insan yetiştirme) izah edilmektedir (s. 219). Burada bir yalınlık veya saflı arayışı dikkat çekmektedir. Cumhuriyet Türkiyesi Osmanlı musikisini katıksız/saf bulmamış ve sadece Türklere ait olduğunu iddia ettiği yeni bir musikinin yaygınlık kazanması için gayret göstermiştir. Bu noktada Ziya Gökalp tekrardan bir referans kaynağıdır. Zira Gökalp’e göre klasik Türk müziği esasında Türk değildir, içinde Bizans, Acem ve Arap unsurlardan nüveler taşımaktadır. Gökalp'in "hars-medeniyet" ikiliği burada da devreye girer ve halk müziği harsın, Batı müziği ise "yeni medeniyet"in türleri olarak tasnif edilir. Böylece klasik musikî dışlanırken halk müziği ve Batı müziğine "kapı arala”nır (s. 223).

Kitap sanat sosyolojisine metodolojik ve tarihsel bir yaklaşım sunmasının yanı sıra Türk modernleşmesi ile ilgili de önemli tespit ve referanslar ihtiva etmektedir. Sanat sosyolojisine nasıl yaklaşılması gerektiği, sanat sosyolojisinin epistemolojik mirasının ne olduğu hakkında bilgiler içermekte ve klasik sosyoloji 
geleneğinin sanat sosyolojisine yapabileceği katkıları yeterince ele almaktadır. Çalışma ayrıca sanat sosyolojisini analitik bir gözle okumayı kolaylaştırmaktadır. Öte yandan sanat sosyolojisinin edebiyat sosyolojisine indirgenmemesi gerektĭğinin altını çizmesi de önemlidir. Ayrıca kitapta sanat ve Türk modernleşmesi arasındaki ilişki ele alınırken, Ziya Gökalp gibi ilk dönem Türk sosyologlarının modernleşmeye farklı kollardan nasıl etki ettiği de gösterilmektedir. 